Prepared for the U.S. Department of Energy

under Contract DE-AC05-76RL01830

\title{
Soil Water Retention and Relative Permeability for Full Range of Saturation
}

F Zhang

September 2010

Pacific Northwest

NATIONAL LABORATORY

Proudly Operated by Battelle Since 1965 


\title{
DISCLAIMER
}

This report was prepared as an account of work sponsored by an agency of the United States Government. Neither the United States Government nor any agency thereof, nor Battelle Memorial Institute, nor any of their employees, makes any warranty, express or implied, or assumes any legal liability or responsibility for the accuracy, completeness, or usefulness of any information, apparatus, product, or process disclosed, or represents that its use would not infringe privately owned rights. Reference herein to any specific commercial product, process, or service by trade name, trademark, manufacturer, or otherwise does not necessarily constitute or imply its endorsement, recommendation, or favoring by the United States Government or any agency thereof, or Battelle Memorial Institute. The views and opinions of authors expressed herein do not necessarily state or reflect those of the United States Government or any agency thereof.

\author{
PACIFIC NORTHWEST NATIONAL LABORATORY \\ operated by \\ BATTELLE \\ for the \\ UNITED STATES DEPARTMENT OF ENERGY \\ under Contract DE-AC05-76RL01830 \\ Printed in the United States of America \\ Available to DOE and DOE contractors from the \\ Office of Scientific and Technical Information, \\ P.O. Box 62, Oak Ridge, TN 37831-0062; \\ ph: (865) 576-8401 \\ fax: (865) 576-5728 \\ email: reports@adonis.osti.gov \\ Available to the public from the National Technical Information Service, \\ U.S. Department of Commerce, 5285 Port Royal Rd., Springfield, VA 22161 \\ ph: (800) 553-6847 \\ fax: (703) 605-6900 \\ email: orders@ntis.fedworld.gov \\ online ordering: http://www.ntis.gov/ordering.htm
}




\title{
Soil Water Retention and Relative Permeability for Full Range of Saturation
}

\author{
F Zhang
}

September 2010

Prepared for

the U.S. Department of Energy

under Contract DE-AC05-76RL01830

Pacific Northwest National Laboratory

Richland, Washington 99352 



\section{Executive Summary}

Common conceptual models for unsaturated flow often rely on the oversimplified representation of medium pores as a bundle of cylindrical capillaries and assume that the matric potential is attributed to capillary forces only. The adsorptive surface forces are ignored. It is often assumed that aqueous flow is negligible when a soil is near or at the residual water content. These models are successful at high and medium water contents but often give poor results at low water contents. These models do not apply to conditions at which water content is less than the residual water content. We extend the lower bound of existing water-retention functions and conductivity models from residual water content to the oven-dry condition (i.e., zero water content) by defining a state-dependent, residual-water content for a soil drier than a critical value. Furthermore, a hydraulic conductivity model for smooth uniform spheres was modified by introducing a correction factor to describe the film flow-induced hydraulic conductivity for natural porous media. The total unsaturated hydraulic conductivity is the sum of those due to capillary and film flow. The extended retention and conductivity models were verified with six datasets from the literature. Results show that, when the soil is at high and intermediate water content, there is no difference between the un-extended and the extended models; when the soil is at low water content, the un-extended models overestimate the water content but under-estimate the conductivity while the extended models match the retention and conductivity measurements well. 



\section{Contents}

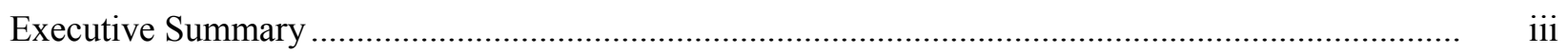

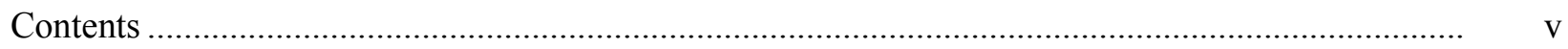

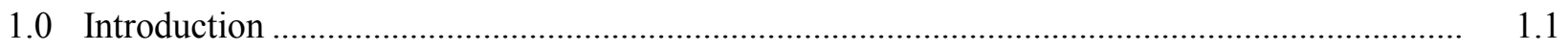

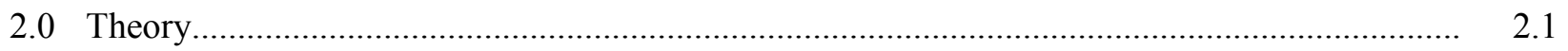

2.1 Classical Models of Water Retention and Conductivity .................................................. 2.1

2.2 Water Retention for Full-Range Saturation................................................................... 2.1

2.3 Hydraulic Conductivity for Full-Range Saturation ........................................................... 2.3

2.3.1 Hydraulic Conductivity Due to Capillary Flow ....................................................... 2.4

2.3.2 Hydraulic Conductivity Due to Film Flow............................................................. 2.4

2.4 Determination of the Critical Pressure and Critical Water Content ..................................... 2.5

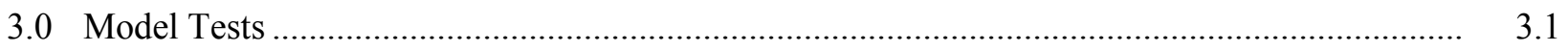

3.1 Measured Hydraulic Properties ................................................................................... 3.1

3.2 The Un-Extended and Extended Retention Models …………........................................... 3.1

3.3 The Capillary and Film Hydraulic Conductivity Models.................................................... 3.2

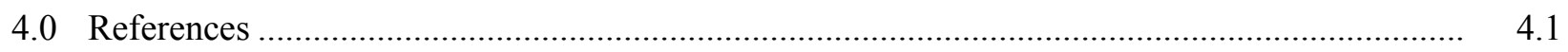

\section{Figures}

2.1. Schematic of the Water Retention and Residual Water Content of (a) the Un-Extended Model and (b) the Extended Model

3.1. The Water Retention (A) and Hydraulic Conductivity (B) of the Gilat Loam (soil \#1 in Table 3.1).

3.2. The Water Retention (A) and Hydraulic Conductivity (B) of the Silt Loam (soil \#2 in Table 3.1)

3.3. The Water Retention (A) and Hydraulic Conductivity (B) of the Clay Loam (soil \#3 in Table 3.1).

3.4. The Water Retention (A) and Hydraulic Conductivity (B) of the Sandy Loam (soil \#4 in Table 3.1).

3.5. The Water Retention (A) and Hydraulic Conductivity (B) of the Adelanto Soil (soil \#5 in Table 3.1)

3.6. The Water Retention (A) and Hydraulic Conductivity (B) of the Pochappa Soil (soil \#6 in Table 3.1)

3.7. The Correction Factor for Film Flow Versus the Effective Grain Diameter... 


\section{Tables}

3.1. Fitted Hydraulic Parameters and Calculated Critical Pressure Head and Water Content............ $\quad 3.2$

3.2. Hydraulic Parameters for the Film Hydraulic Conductivity Model........................................... 3.3

3.3. Root of the Mean Squared Error (RMSE) of the Retention and Hydraulic Conductivity Models 


\subsection{Introduction}

This report describes the soil water retention and relative permeability functions for conditions from oven-dry to full saturation. These functions were developed as part of the Remediation Decision Support of the Groundwater Remediation Project, managed by CH2MHILL Plateau Remediation Company, Inc., Richland, Washington. The purpose of the development is to better describe water movement under dry conditions such as those at the Hanford site.

Common conceptual models for unsaturated flow often rely on the oversimplified representation of medium pores as a bundle of cylindrical capillaries and assume that soil water pressure head is attributed to capillary forces only and ignores the adsorptive surface forces. Hence, it is often assumed that aqueous flow is negligible when a soil is near or at a residual water content, $\theta_{\mathrm{r}}$. The reason for the finite value of $\theta_{r}$ is that the dominant historical water-content measurements were in the wet range, and the typical soil water retention models assumed asymptotic behavior at low water content values. It is generally treated as a fitting parameter. Hence, an effective saturation is often defined as $S_{e}=\left(\theta-\theta_{r}\right) /\left(\theta_{\mathrm{s}}-\theta_{\mathrm{r}}\right)$ with $\theta$ being water content and $\theta_{\mathrm{s}}$ the saturated water content. Effective saturation is then used in the soil water retention function, $h\left(S_{e}\right)$, with $h$ being the pressure head, and in the relative permeability function, $k_{r}\left(S_{e}\right)$. Various commonly used models have been developed to describe the $\mathrm{h}\left(\mathrm{S}_{\mathrm{e}}\right)$ (e.g., Brooks and Corey 1964, van Genuchten 1980) and the $\mathrm{k}_{\mathrm{r}}\left(\mathrm{S}_{\mathrm{e}}\right)$ (e.g., Burdine 1954, Mualem 1976a) relationships. These functions are successful at high and medium water contents but often give poor results at low water contents. These models do not apply to conditions at which $\theta$ is less than $\theta_{\mathrm{r}}$, e.g., the infiltration process into a soil with initial water content $\theta_{\mathrm{i}}<\theta_{\mathrm{r}}$, the evaporation process with a dry layer of soil at the ground surface, or the soil desiccation process with a heat source. Consequently, these processes cannot be simulated correctly if a model with constant residual water content is used.

A few researchers have tried to extend the $h(\theta)$ relation to the oven-dry condition. Ross et al. (1991) proposed a correction of the Campbell (1974) model that makes water content $\theta=0$ at a finite value of pressure head $h_{d}$. Campbell and Shiozawa (1992) modified the van Genuchten (1980) model for improving fits to dry range data. Rossi and Nimmo (1994) developed two models that fit the entire range from saturation to over-dryness. Fayer and Simmons (1995) extended the van Genuchten relationship to the oven-dry condition by replacing the constant residual saturation with a variable that is log-linear to the pressure head $\mathrm{h}$. The above models require a refitting of the revised curves to the data. Webb (2000) extended the van Genuchten model to the oven-dry condition with a log-linear relationship by using actual saturation, $S=\theta / \theta_{\mathrm{s}}$, instead of the effective saturation, and the extension does not require any refitting of parameters.

There is little attempt to extend the relative permeability function to the full range of saturation. Rossi and Nimmo (1994) and Fayer and Simmons (1995) simply replaced effective saturation by actual saturation in the Mualem model. This leads to an overestimation of $\mathrm{k}_{\mathrm{r}}$ at high and intermediate water content. Tuller and Or (2001) proposed a model of unsaturated hydraulic conductivity due to film and corner flow. The model is mathematically very complex and is not compatible with the commonly used retention models. Peters and Durner (2008) presented a new model that combines a simple film flow function with the capillary flow model of Mualem. To use the model, additional parameters must be known to quantify the contribution of film flow. 
This report extends the lower bound of the existing retention and relative permeability models from residual water content, $\theta_{\mathrm{r}}$, to zero water content. The theory is presented in Section 2, followed by the model test in Section 3. 


\subsection{Theory}

This section describes the mathematical expressions of soil water retention and the unsaturated hydraulic conductivity. For brevity, the unsaturated hydraulic conductivity may also be simply referred to as hydraulic conductivity or conductivity.

\subsection{Classical Models of Water Retention and Conductivity}

The Brooks and Corey (1964) and the van Genuchten (1980) models are two commonly used water retention functions (WRFs):

$$
\begin{gathered}
S_{e}(h)=\left(h_{e} / h\right)^{\lambda} \quad|h|>\left|h_{e}\right| \\
S_{e}(h)=\left[1+(\alpha|h|)^{n}\right]^{-m}
\end{gathered}
$$

where $h_{e}$ is the air-entry pressure head, and $\alpha$ is a fitting parameter that is inversely proportional to the pressure suction at air-entry; $\lambda$ and $n$ are fitting parameters related to particle-size distribution; and $m$ is a constant that is commonly approximated by $m=1-1 / n$ (van Genuchten 1980). The above WRFs generally perform well at high and intermediate $\theta$ but poorly in low $\theta$; they do not apply to conditions when $\theta \leq \theta_{r}$. Although it is possible to set $\theta_{r}=0$ so that the above WRFs can apply to the full range of soil wetness, the WRFs usually do not perform the best if $\theta_{\mathrm{r}}=0$ is enforced. The hydraulic conductivity due to capillary flow is commonly defined by an expression of the form (Zhang et al. 2003)

$$
K_{i}^{c a p}\left(S_{e}\right)=K_{s i} S_{e}^{L_{i}}\left[\frac{\int_{0}^{S_{e}}\left(h^{-\beta} d S_{e}\right)}{\int_{0}^{1}\left(h^{-\beta} d S_{e}\right)}\right]^{\gamma}, i=1,2, \text { or } 3
$$

where $i$ denotes one of the three principal directions, $L$ is a connectivity-tortuosity coefficient, and $\beta$ and $\gamma$ are constants. Equation (2.2) reduces to the Burdine (1953) relationship when $\beta=2$ and $\gamma=1$ and to the Mualem (1976a) relationship when $\beta=1$ and $\gamma=2$.

\subsection{Water Retention for Full-Range Saturation}

The concept of a commonly used WRF (e.g., Eq. 2.1) is shown schematically in Figure 2.1a. For these models, the soil water content is never less than $\theta_{r}$ regardless of the pressure head value. These commonly used models will be referred to as the un-extended models to distinguish them from their extended version that can apply to conditions from saturation to zero water content.

To describe the $\theta(h)$ relationship for the full-range of water content, we conceptualize soil water flow as a combination of capillary and film flow. Hence, the $\theta(h)$ curve is divided into segments I and II (Figure 2.1b). We define the pressure head dividing the two segments as the critical pressure head, $h_{c}$, and the water content corresponding to $h_{c}$ as the critical water content, $\theta_{c}$. Details for determining $h_{c}$ and 
$\theta_{c}$ will be given in Section 2.4. When a soil is wetter than $\theta_{c}, \theta_{\mathrm{r}}$ is a constant and water may move dominantly as capillary flow. The $\theta(h)$ relationship is described by the un-extended model. When the soil is drier than $\theta_{c}$, water may move dominantly as film flow, and the $\theta(h)$ relationship tends to obey the adsorption-based or similar model.
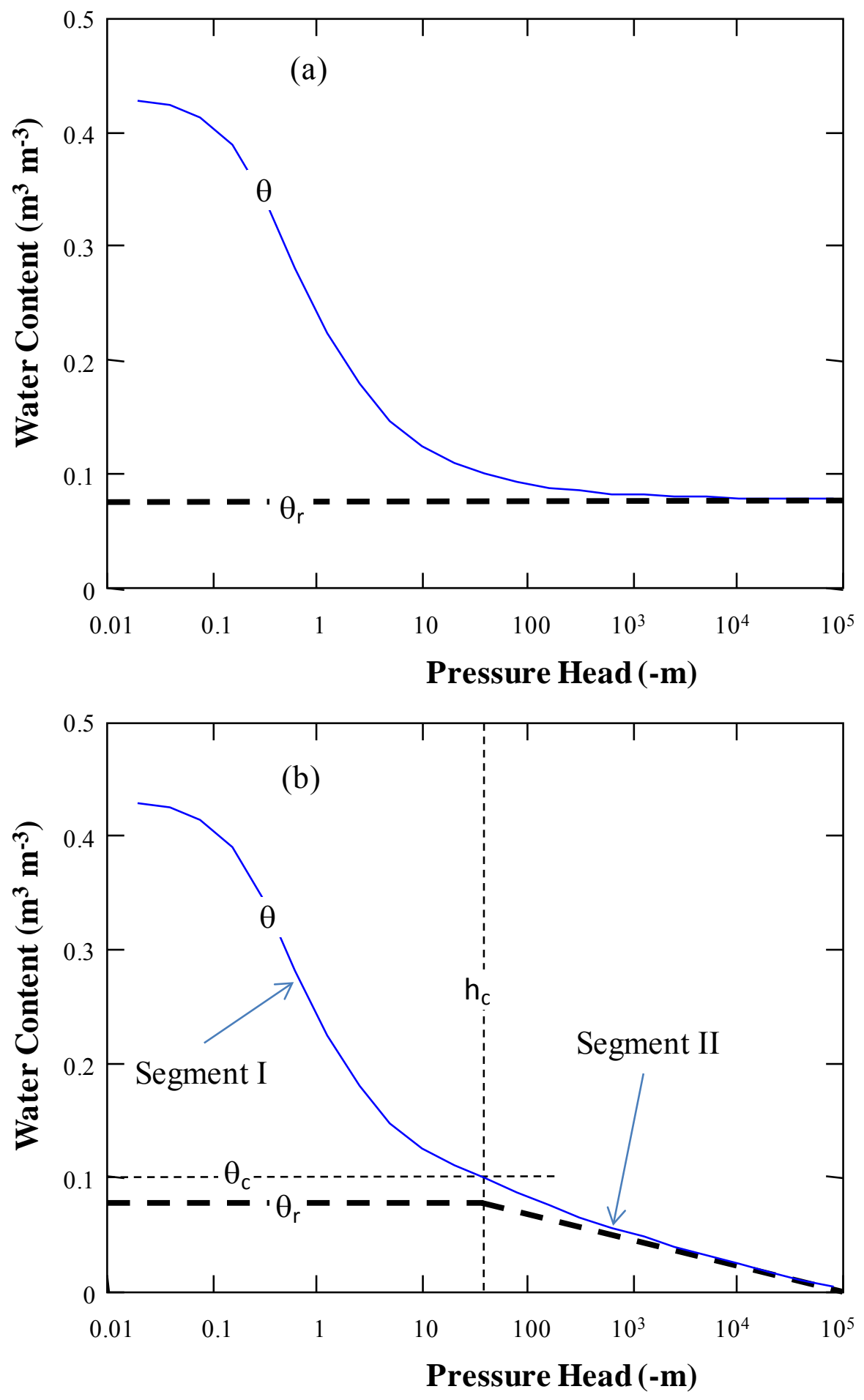

Figure 2.1. Schematic of the Water Retention and Residual Water Content of (a) the Un-Extended Model and (b) the Extended Model 
Segment II of the $\theta(h)$ curve may be described in different ways. A simple way is to use the adsorption-based model to replace the un-extended model (Campbell and Shiozawa 1992). However, because the residual water content is not a constitutional parameter in the adsorption-based model, the effective saturation cannot be defined, and hence, the extended WRC in this way is not compatible with the commonly used relative permeability models. Moreover, the adsorption model is not continuous at $h_{d}$, i.e., the soil water condition for $|\mathrm{h}|>\left|\mathrm{h}_{\mathrm{d}}\right|$ is undefined. To circumvent this problem, we used the adsorption-based model (Campbell and Shiozawa 1992) to describe $\theta_{r}$, instead of $\theta$, when the pressure head is less than a critical value $h_{c}$ as shown in Figure 2.1b:

$$
\theta_{r}(h)=\theta_{r 0} \xi(h)
$$

and

$$
\xi(h)=\left\{\begin{array}{cc}
0 & \text { if }|h| \geq\left|h_{d}\right| \\
\frac{\ln \left(h_{d} / h\right)}{\ln \left(h_{d} / h_{c}\right)} & \text { if }\left|h_{c}\right|<|h|<\left|h_{d}\right| \\
1 & \text { if }|h| \leq\left|h_{c}\right|
\end{array}\right.
$$

where $\xi$ is a correction factor, $\theta_{r 0}$ is the residual water content for the un-extended model and is a constant. The modified effective soil water saturation, $S_{e}{ }^{*}$, is then defined as

$$
S_{e}^{*}=\frac{\theta-\theta_{r 0} \xi(h)}{\theta_{s}-\theta_{r 0} \xi(h)}
$$

After we redefine the effective saturation, Eq. (2.1), without the need of making any change, it can now be used to describe the extended water-retention curve. The extended Brooks and Corey (1964) and van Genuchten (1980) WRFs expressed as $\theta(h)$ relationships are obtained by substituting Eq. (2.4) into (2.1a) and (2.12b), respectively, and rearranging the terms as

$$
\begin{gathered}
\theta(h)=\theta_{r 0} \xi(h)+\left[\theta_{s}-\theta_{r 0} \xi(h)\right]\left(h_{e} / h\right)^{\lambda} \quad|h|>\left|h_{e}\right| \\
\theta(h)=\theta_{r 0} \xi(h)+\left[\theta_{s}-\theta_{r 0} \xi(h)\right]\left[1+(\alpha|h|)^{n}\right]^{-m}
\end{gathered}
$$

Equations (2.5a) and (2.5b) reduce to the classic definition of effective saturation when $|h| \leq\left|h_{c}\right|$.

\subsection{Hydraulic Conductivity for Full-Range Saturation}

For a more accurate description of the flow rate at a low water content, both capillary flow and film flow need to be considered. We assume that both the capillary flow and film flow exist at the full range of saturation. However, as will be shown in Section 3.0, the contribution of film flow to the total flow is negligible at high and intermediate water content; and vice versa, the contribution of capillary flow to the total flow is negligible at low water content. 


\subsubsection{Hydraulic Conductivity Due to Capillary Flow}

After redefining the effective saturation in Eq. (2.4), the contribution to the hydraulic conductivity due to capillary flow can be determined using the classical model [e.g., Eq. (2.2)] combined with the extended WRF:

$$
\begin{gathered}
K^{\text {cap }}\left(S_{e}^{*}\right)=K\left(S_{e}^{*}\right) \\
K^{c a p}(h)=K(h)
\end{gathered}
$$

For example, after incorporating the van Genuchten function into the Mualem (1976a) model, the relative permeability as a function of $S_{e}{ }^{*}$ is given as

$$
K^{c a p}\left(S_{e}\right)=K_{s} S_{e}^{* L}\left[1-\left(1-S_{e}^{* 1 / m}\right)^{m}\right]^{2}
$$

\subsubsection{Hydraulic Conductivity Due to Film Flow}

Tokunaga (2009) developed a formula for estimating hydraulic conductivity due to film flow in smooth uniform spheres by combining Langmuir's film model (Bird et al. 1960) with scaling analysis. Here we adapt the Tokunaga (2009) formula to natural porous media by introducing a soil-dependent correction factor as

$$
K^{f i l m}(h)=f K_{s}^{f i m}\left(1+\frac{\rho g d_{g}|h|}{2 \sigma}\right)^{-1.5}
$$

where

$$
K_{s}^{f i l m}=b(1-\phi) \sqrt{d_{g}}, b=\frac{\sqrt{2} \pi^{2} \rho g}{\eta}\left(\frac{\varepsilon \varepsilon_{0}}{2 \sigma}\right)^{1.5}\left(\frac{k_{b} T}{z e}\right)^{3}
$$

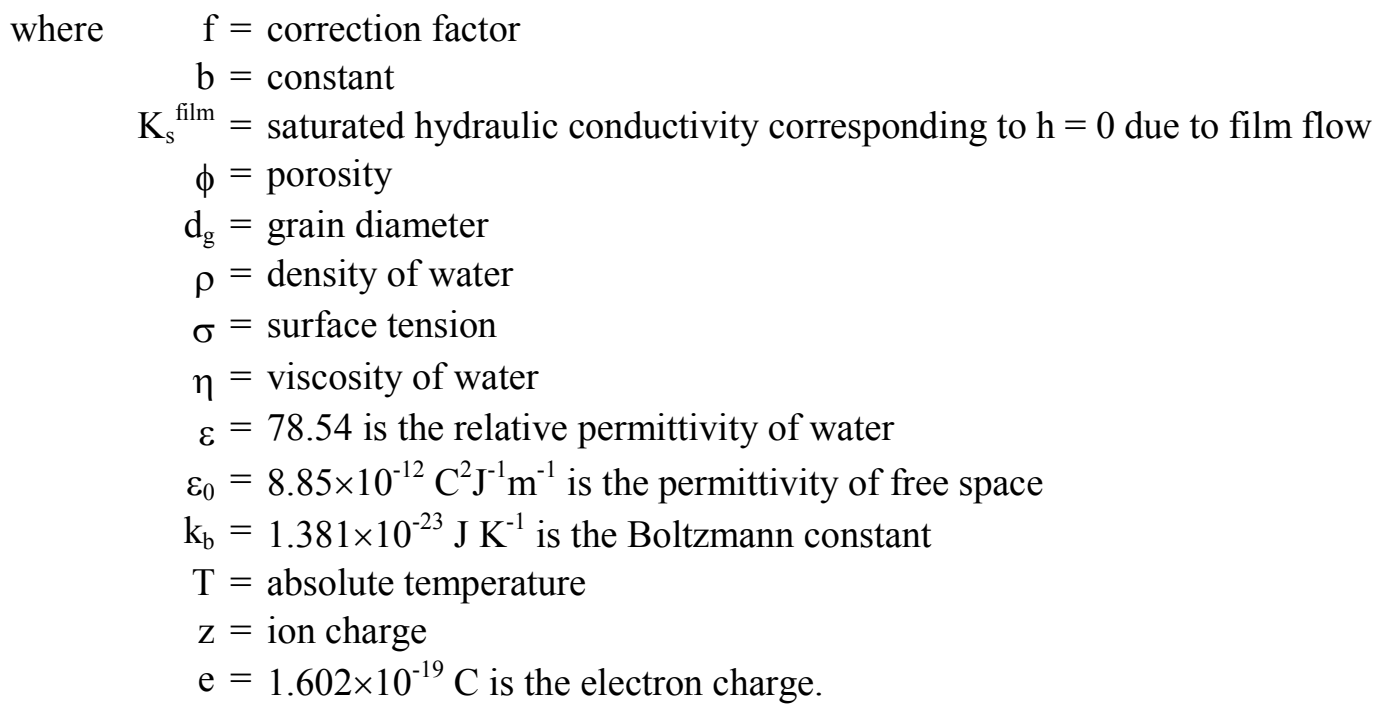


With the constants given, we can obtain $\mathrm{b}=7.649 \times 10^{-10} \mathrm{~m}^{0.5} \mathrm{~s}^{-1}$ at $20^{\circ} \mathrm{C}$ (assuming $\mathrm{z}=1$ ). The model for thick film in Tuller and Or (2001) had a similar basis as the above model. The model presented by Liu (2004) is also similar to Eq. (2.8).

Assuming $\mathrm{f}=1$ (i.e., no correction), the only parameters needed to determine $\mathrm{K}^{\text {film }}$ and $\mathrm{K}_{\mathrm{s}}^{\text {film }}$ are porosity and grain diameter. For example, for a sandy soil with $\mathrm{d}_{\mathrm{g}}=0.1 \mathrm{~mm}$ and $\phi=0.35$,

$\mathrm{K}_{\mathrm{s}}^{\text {film }}=5.0 \times 10^{-12} \mathrm{~m} \mathrm{~s}^{-1}$; for a silty soil with $\mathrm{d}_{\mathrm{g}}=0.01 \mathrm{~mm}$ and $\phi=0.35, \mathrm{~K}_{0}^{\text {film }}=1.6 \times 10^{-12} \mathrm{~m} \mathrm{~s}^{-1}$. These values are generally many orders of magnitude smaller than the saturated hydraulic conductivity because of capillary flow, indicating that the contribution of film flow to the total is usually very small and negligible under saturated conditions. However, when the soil is very dry and capillary flow becomes very small, the contribution from film flow can be significant or even dominant.

The total hydraulic conductivity is the sum of the contributions due to capillary flow [Eq. (2.6)] and film flow [Eq. (2.8)]:

$$
K(h)=K^{\text {cap }}(h)+K^{\text {film }}(h)
$$

\subsection{Determination of the Critical Pressure and Critical Water Content}

As mentioned above, the WRC is divided into two segments, I and II, at a critical point $\left(h_{c}, \theta_{c}\right)$. Fisher (1926) derived the critical pressure head for close-packed spheres as $h_{c} \approx-9.1 \sigma / \rho g d_{g}$ (Tokunaga 2009), with $\sigma$ being the surface tension. This indicates that the critical pressure head is inversely proportional to grain diameter, and finer materials will have smaller (more negative) $h_{c}$. For example, assuming that $\sigma=0.072 \mathrm{~N} \mathrm{~m}^{-1}$, for a silty soil with a mean particle diameter of $0.01 \mathrm{~mm}$, the estimated critical pressure head is $-6.7 \mathrm{~m}$. However, the Fisher (1926) formula for smooth spheres may not apply to natural porous media.

For keeping a smooth water-retention curve, we followed the procedures in Web (2000) but presented them in a slightly different way. We $\log$-transformed $h$ as $Z=\ln (h)$ and hence $Z_{d}=\ln \left(h_{d}\right), Z_{c}=\ln \left(h_{c}\right)$; the WRF is then expressed as $\theta(Z)$. For a smooth transition of the two WRC segments, the tangent line (i.e., the first derivative) on the $\theta(Z)$ curve through the critical point is enforced to pass the point corresponding to the oven-dry condition, i.e., $(Z, \theta)=\left(Z_{d}, 0\right)$. Hence, the slope at the critical point can be determined by differentiating Eq. (2.5) for segment I:

$$
\frac{d \theta}{d Z}=-\frac{n m\left(\theta_{s}-\theta_{r 0}\right) \alpha^{n} e^{n Z_{c}}}{\left(1+\alpha^{n} e^{n Z_{c}}\right)^{m+1}}
$$

Because the tangent line passes through the point corresponding to the oven-dry condition, the slope of this tangent line can also be calculated as $\theta_{\mathrm{c}} /\left(\mathrm{Z}_{\mathrm{c}}-\mathrm{Z}_{\mathrm{d}}\right)$ (Figure $\left.2.1 \mathrm{~b}\right)$. As we know, $\theta_{c}$ satisfies Eq. (2.5). Thus

$$
\frac{d \theta}{d Z}=\frac{1}{Z_{c}-Z_{d}}\left[\theta_{r 0}+\left(\theta_{s}-\theta_{r 0}\right)\left(1+\alpha^{n} e^{n Z_{c}}\right)^{-m}\right]
$$


$\mathrm{Z}_{\mathrm{c}}$ can be solved numerically by equating (2.10) and (2.11), for example, using the root function in $\operatorname{MathCad}^{\circledR}$. The critical pressure head is then calculated using $h_{c}=\exp \left(Z_{c}\right)$, and the critical water content $\theta_{c}$ is determined using Eq. (2.5). Occasionally, when the residual water content is very high, for example, for clayey soils, fixing an $h_{d}$ of $10^{5} \mathrm{~m}$ may not yield a solution of $Z_{c}$. In this case, $h_{d}$ may be relaxed to $10^{6} \mathrm{~m}$ or larger. 


\subsection{Model Tests}

This section tests the extended retention and hydraulic conductivity models using the selected measurements from the literature.

\subsection{Measured Hydraulic Properties}

To verify the new models, we used six datasets from the literature that contain measurements of both $\theta(h)$ and $K$; some of the $\theta(h)$ or $\mathrm{K}$ data were measured under the conditions at or drier than $-150 \mathrm{~m}$ pressure head. The selected measurements are briefly summarized below.

Pachepsky et al. (1984) reported the unsaturated hydraulic properties for a few soils, three of which were measured at the pressure head as low as about $-2000 \mathrm{~m}$ (Figure 3 of Pachepsky et al. 1984). The unsaturated hydraulic properties of the Gilat loam reported in Mualem (1976b) were measured down to the pressure head of about $-1500 \mathrm{~m}$. (These data may also be found in Tuller and Or 2001, or in Peters and Durner 2008).

Jackson et al. (1965) measured the soil water retention properties of the Adelanto loam and the Pochappa loam with pressure plates at high water content and pressure membranes at low water content by equilibration with saturated salt solution. The water contents were measured at different pressure head from near zero to as low as $-2.5 \times 10^{4} \mathrm{~m}$ for the Adelanto loam and to $-3.1 \times 10^{4} \mathrm{~m}$ for the Pochappa loam. They also summarized the unsaturated hydraulic conductivity of the Pochappa loam in Gardner and Miklich (1962) and determined the K of both soils from diffusivity measurement reported in Jackson $(1963,1964)$. These results are reported in the Figures 5 and 6 of Jackson et al. (1965) and were digitized for our use.

\subsection{The Un-Extended and Extended Retention Models}

As mentioned above, the extended water retention model does not introduce any additional parameters because the critical water content and critical pressure head are calculated from other parameters. However, although it is possible, direct fitting the extended model to the $h(\theta), K(\theta)$ and/or $K(\psi)$ measurements is not straightforward due to the introduction of $\theta_{c}$ and $h_{c}$. Here, we fit the hydraulic parameters for the un-extended retention model using only measurements under the conditions wetter than $-150 \mathrm{~m}$ pressure. The rest of the measurements were used to test the extended model. Parameter $\theta_{s}$ was directly determined based on measurements. Parameters $\alpha, n$, and $\theta_{r}$ of the van Genuchten model were optimized to the $\theta(h)$ data.

The measured retention and conductivity for the soils selected were described using both the unextended and extended models as shown in Figure 3.1 through Figure 3.6. For soils \#1, \#5, and \#6, the extended retention model showed significantly improved matching to data at low water content (Figures 3a, 6a, and 7a); when $|\mathrm{h}| \leq\left|\mathrm{h}_{\mathrm{c}}\right|$, the un-extended and extended models are identical; when $|\mathrm{h}|>\left|\mathrm{h}_{\mathrm{c}}\right|$, the unextended model generally gives a water content no less than $\theta_{\mathrm{r}}$ regardless of pressure head, while the water content from the extended model decreases with increasing $\ln (|\mathrm{h}|)$ from $\theta_{\mathrm{c}}$ to zero. For example, Figure 3.2a shows that, when the soil is wetter than $-5.1 \mathrm{~m}$ pressure head, both the un-extended and extended van Genuchten models can describe the retention curve of the Galit loam equally well; when the 
soil is drier than $-5.1 \mathrm{~m}$ pressure head, the un-extended model generally gives a water content ranging between 0.1 and 0.106 , which are very different from the measurements; the water content from the extended model decreases with increasing $\ln (|\mathrm{h}|)$ from 0.106 to zero and matches the measurements very well. For soils \#2, \#3, and \#4, their residual water contents were zero or near zero, and hence an extension is not needed. Table 3.3 lists the fitting error expressed as the root of the mean squared error (RMSE) of water content. Comparing this with the RMSE of the un-extended model, the fitting errors of the extended model were reduced by $57 \%$ to $82 \%$ for soils $\# 1$, $\# 5$, and $\# 6$ where the fitting error was the same for soils \#2, \#3, and \#4.

The fitted hydraulic parameters, the calculated critical pressure head, and the critical water content are summarized in Table 3.1. The same set of parameters (i.e., $\theta_{\mathrm{s}}, \theta_{\mathrm{r} 0}, \alpha, \mathrm{n}, \mathrm{K}_{\mathrm{s}}$, and $\mathrm{L}$ ) can be used for both the un-extended and extended retention models and the capillary flow-based hydraulic conductivity model. The critical water contents for these soils varied between 0.014 for the sandy loam and $0.178 \mathrm{~m}^{3} \mathrm{~m}^{-3}$ for the Adelanto loam, which are larger than (i.e., by 0.007 to $0.135 \mathrm{~m}^{3} \mathrm{~m}^{-3}$ ) the $\theta_{\mathrm{r}}$ values of corresponding soils. The critical pressure head varied between $-5.1 \mathrm{~m}$ for the Gilat loam and $-4006 \mathrm{~m}$ for the silt loam.

The critical pressure heads estimated by the Fisher (1926) formula are -0.67 and $-67 \mathrm{~m}$ for soils with mean particle diameters of $0.1 \mathrm{~mm}$ and $0.001 \mathrm{~mm}$, respectively. Tuller and Or (2001) developed a porescale model and found that film flow dominates capillary flow at a relative high pressure head (approximately -10 to $-30 \mathrm{~m}$ ). For the Gilat, Adelanto, and Pochappa loams, the $\mathrm{h}_{\mathrm{c}}$ values are at the same order of magnitude as those from Tuller and Or (2001) and Tokunaga (2009). However, for the three soils in from Pachefsky et al. (1984), the $h_{c}$ values look much smaller than the others. This is due to their very small $\theta_{\mathrm{r}}$ values (i.e., 0 to $0.007 \mathrm{~m}^{3} \mathrm{~m}^{-3}$ ), which are unusual for loamy soils.

Table 3.1. Fitted Hydraulic Parameters and Calculated Critical Pressure Head and Water Content

\begin{tabular}{|c|c|c|c|c|c|c|c|c|c|c|}
\hline Soil \# & $\begin{array}{c}\text { Soil/Sample } \\
\text { Name }\end{array}$ & $\begin{array}{c}\theta_{\mathrm{s}} \\
\left(\mathrm{m}^{3} \mathrm{~m}^{-3}\right) \\
\end{array}$ & $\begin{array}{c}\theta_{\mathrm{r}} \\
\left(\mathrm{m}^{3} \mathrm{~m}^{-3}\right) \\
\end{array}$ & $\begin{array}{c}\alpha \\
\left(\mathrm{m}^{-1}\right)\end{array}$ & $\begin{array}{c}n \\
(-)\end{array}$ & $\begin{array}{c}\mathrm{K}_{\mathrm{s}} \\
\left(\mathrm{m} \mathrm{s}^{-1}\right)\end{array}$ & $\begin{array}{l}\mathrm{L} \\
(-)\end{array}$ & $\begin{array}{l}\mathrm{h}_{\mathrm{c}} \\
(\mathrm{m}) \\
\end{array}$ & $\begin{array}{c}\theta_{\mathrm{c}} \\
\left(\mathrm{m}^{3} \mathrm{~m}^{-3}\right) \\
\end{array}$ & Data Source \\
\hline 1 & Gilat Loam & 0.4 & 0.1 & 1.67 & 2.84 & $1.69 \times 10^{-7}$ & 1.75 & -5.1 & 0.106 & Mualem 1976b \\
\hline 2 & Silt Loam & 0.53 & 0 & 0.764 & 1.31 & $1.90 \times 10^{-6}$ & 1.29 & -4006 & 0.044 & Pachefsky et al. 1984 \\
\hline 3 & Clay Loam & 0.50 & 0 & 0.655 & 1.21 & $3.35 \times 10^{-6}$ & 1.48 & -820 & 0.135 & Pachefsky et al. 1984 \\
\hline 4 & Sandy Loam & 0.43 & 0.007 & 1.32 & 1.51 & $2.94 \times 10^{-7}$ & -0.234 & -2204 & 0.014 & Pachefsky et al. 1984 \\
\hline 5 & Adelanto Loam & 0.423 & 0.158 & 0.321 & 2.11 & $5.82 \times 10^{-7}$ & 0.47 & -31.9 & 0.178 & Jackson et al. 1965 \\
\hline 6 & Pochappa Loam & 0.441 & 0.077 & 0.648 & 2.32 & $2.45 \times 10^{-6}$ & 2.35 & -28.4 & 0.085 & Jackson et al. 1965 \\
\hline
\end{tabular}

\subsection{The Capillary and Film Hydraulic Conductivity Models}

With the retention parameters being fixed, $K_{s}$ and $L$ were then fitted to the $K(\theta)$ and/or $K(h)$ data at high and intermediate $\theta$ or $h$. With the fitted $\mathrm{K}_{\mathrm{s}}$, the effective grain diameter $\mathrm{d}_{\mathrm{g}}$ was estimated using the Kozeny model, and the $\mathrm{K}_{\mathrm{s}}^{\text {film }}$ was determined with Eq. (2.8). The correction coefficient $\mathrm{f}$ for the film flow model was fitted to the $\mathrm{K}$ data at low $\theta$ or h. For soils \#1 to \#4, each $\mathrm{K}(\mathrm{h})$ dataset had an obvious point, which indicates the transition from capillary flow to film flow. For soils $\# 5$ and $\# 6$, only one $\mathrm{K}$ data point at the driest water content was considered to be of film flow.

Figure $3.1 \mathrm{~b}$ through Figure 3.6b compare the measured and predicted conductivity for the six soils. The van Genuchten-Mualem capillary flow model $\mathrm{K}^{\text {cap }}$ can describe the $\mathrm{K}$ curves quite well up to a critical point, beyond which the capillary flow model significantly underpredicts K; contrarily, the film 
flow model $\mathrm{K}^{\text {film }}$ can describe the $\mathrm{K}$ curves when the soil is relatively dry. Consequently, the summation of the capillary and film flow models can predict the whole K curve very well. For example, Figure 3.1b shows that, the capillary flow model can well match the data up to the pressure head of about $-1.5 \mathrm{~m}$, while the film flow model can match the data under the conditions drier than $-1.5 \mathrm{~m}$ pressure head. Consequently, the total of the $\mathrm{K}^{\text {cap }}$ and $\mathrm{K}^{\text {film }}$ model can describe the $\mathrm{K}$ curve of the Gilat loam very well. Table 3.3 lists the fitting error of $\ln (\mathrm{K})$. Comparing these with those of the capillary-based model, the fitting errors were reduced by $52 \%$ to $98 \%$ for soils \#1 to \#4. The fitting error using the capillary model of hydraulic conductivity was infinity when $\theta \leq \theta_{\mathrm{r}}$ for soils \#5 and \#6.

The parameters for the film flow models are summarized in

Table 3.2. The $\mathrm{K}_{\mathrm{s}}^{\text {film }}$ directly calculated using Eq. (2.8) falls in a very narrow range between 1.67 and $2.97 \times 10^{-12} \mathrm{~m} \mathrm{~s}^{-1}$. The fitted correction factor $\mathrm{f}$ varied by two orders of magnitude from 54 to 5341 . It appears that $f$ increases with the effective grain diameter (Figure 3.7) for the limited data available. This indicates that $\mathrm{K}^{\text {film }}$ can be significantly underestimated by the original Tokunaga (2009) model, which was developed for a porous medium of smooth uniform spheres. Natural soil grains are often very rough and in irregular shape, and their grain size may vary a few orders of magnitude. Consequently, a natural porous medium may have a significantly larger surface area conducting film flow than a medium with smooth uniform particles. However, the correction factor may not apply to other soils because the empirical relationship shown in Figure 3.7 was based on limited data, and natural soils or sediments vary significantly.

Table 3.2. Hydraulic Parameters for the Film Hydraulic Conductivity Model

\begin{tabular}{cccccc}
\hline $\begin{array}{c}\text { Soil } \\
\#\end{array}$ & Soil Name & $\begin{array}{c}\mathrm{d}_{\mathrm{g}} \\
(\mathrm{mm})\end{array}$ & $\begin{array}{c}\mathrm{K}_{\mathrm{s}}^{\text {film }} \\
\left(\mathrm{m} \mathrm{s}^{-1}\right)\end{array}$ & $\begin{array}{c}\mathrm{f} \\
(-)\end{array}$ & Data Source \\
\hline 1 & Gilat Loam & 0.013 & $1.67 \times 10^{-12}$ & 45 & Mualem 1976b \\
2 & Silt Loam & 0.023 & $1.71 \times 10^{-12}$ & 964 & Pachefsky et al. 1984 \\
3 & Clay Loam & 0.035 & $2.26 \times 10^{-12}$ & 5341 & Pachefsky et al. 1984 \\
4 & Sandy Loam & 0.015 & $1.68 \times 10^{-12}$ & 64 & Pachefsky et al. 1984 \\
5 & Adelanto Loam & 0.022 & $2.06 \times 10^{-12}$ & 5048 & Jackson et al. 1965 \\
6 & Pochappa Loam & 0.048 & $2.97 \times 10^{-12}$ & 1296 & Jackson et al. 1965 \\
\hline${ }^{\dagger} \mathrm{K}_{\mathrm{s}}^{\text {film }}$ & was determined using Eq. (2.8). & & \\
\hline
\end{tabular}

Table 3.3. Root of the Mean Squared Error (RMSE) of the Retention and Hydraulic Conductivity Models

\begin{tabular}{lccccc}
\hline & & \multicolumn{2}{c}{$\begin{array}{c}\text { RMSE of } \theta \\
\left(\mathrm{m}^{3} \mathrm{~m}^{-3}\right)\end{array}$} & \multicolumn{2}{c}{$\begin{array}{c}\text { RME of } \ln (\mathrm{K}) \\
(-)\end{array}$} \\
\cline { 3 - 6 } Soil & & \multicolumn{3}{c}{ New } \\
$\#$ & Soil Name & VG Model & Model & $\begin{array}{c}\text { Capillary } \\
\text { Model }\end{array}$ & $\begin{array}{c}\text { Capillary+Film } \\
\text { Models }\end{array}$ \\
\hline 1 & Gilat Loam & 0.019 & 0.0081 & 17.56 & 0.37 \\
2 & Silt Loam & 0.013 & 0.013 & 1.64 & 0.64 \\
3 & Clay Loam & 0.022 & 0.022 & 1.49 & 0.72 \\
4 & Sandy Loam & 0.0094 & 0.0094 & 2.19 & 0.81 \\
5 & Adelanto Loam & 0.056 & 0.01 & $\infty^{\dagger}$ & 0.341 \\
6 & Pochappa Loam & 0.032 & 0.0097 & $\infty^{\dagger}$ & 0.411 \\
\hline
\end{tabular}



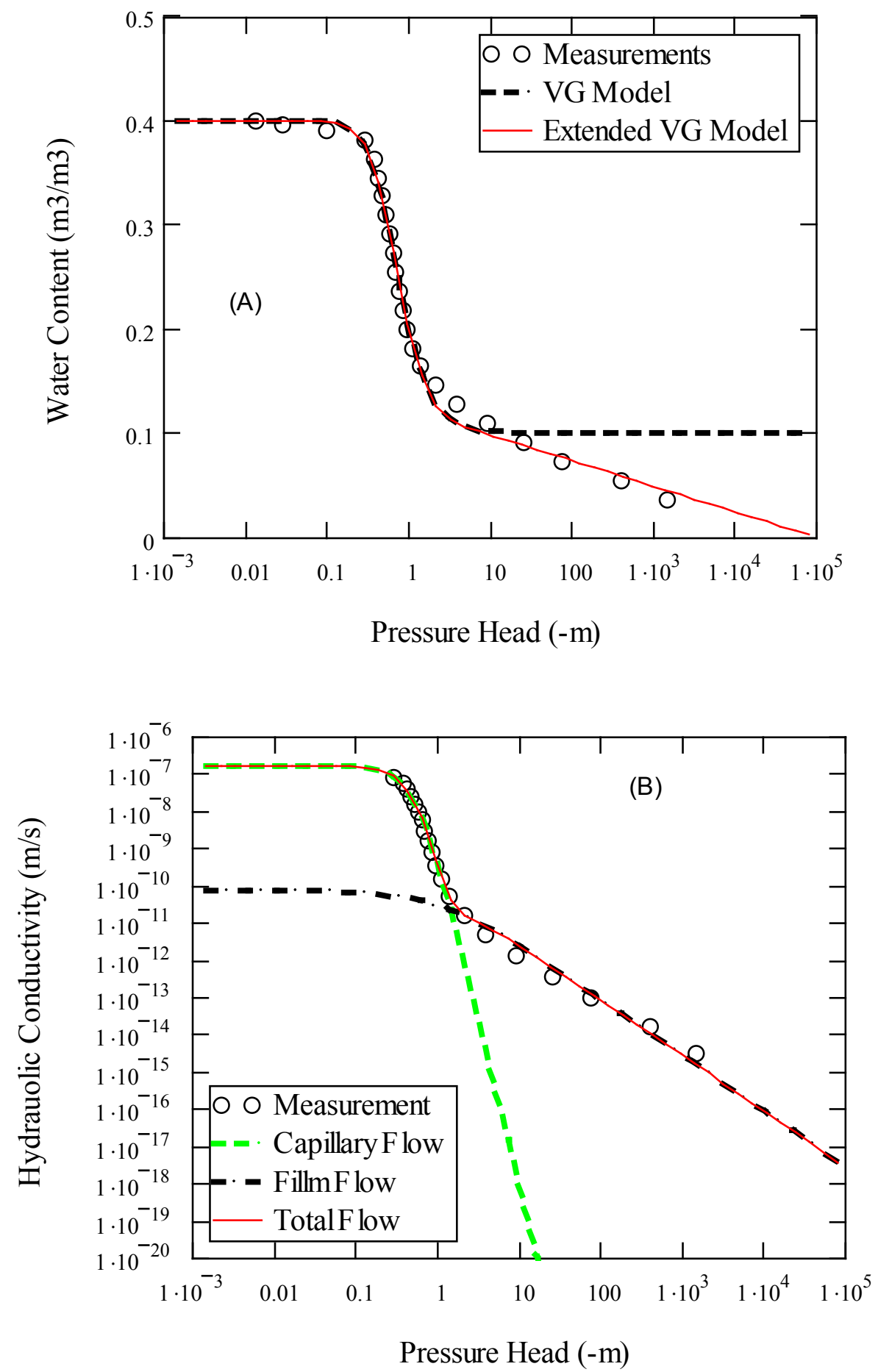

Figure 3.1. The Water Retention (A) and Hydraulic Conductivity (B) of the Gilat Loam (soil \#1 in Table 3.1). 

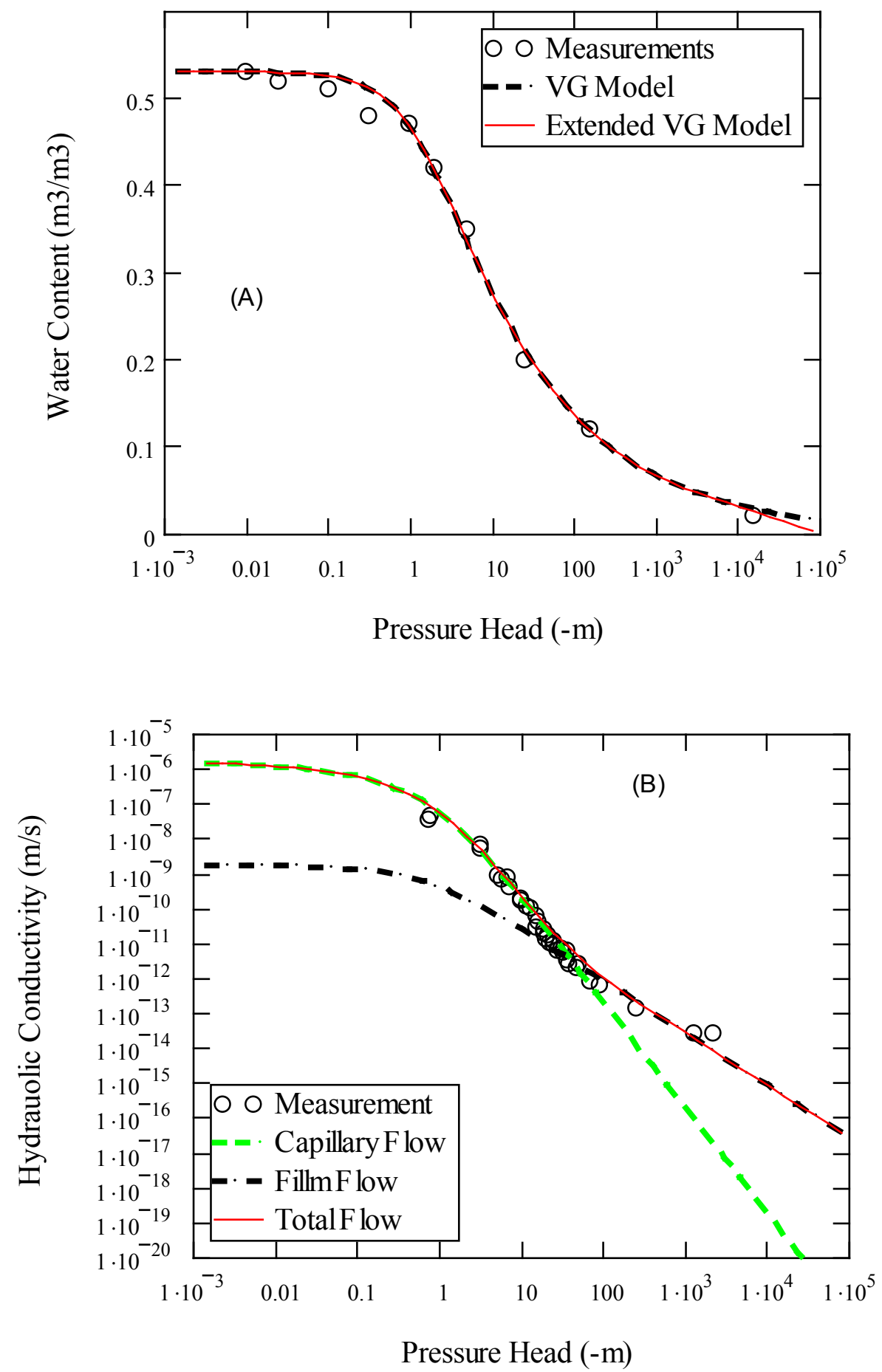

Figure 3.2. The Water Retention (A) and Hydraulic Conductivity (B) of the Silt Loam (soil \#2 in Table 3.1) 

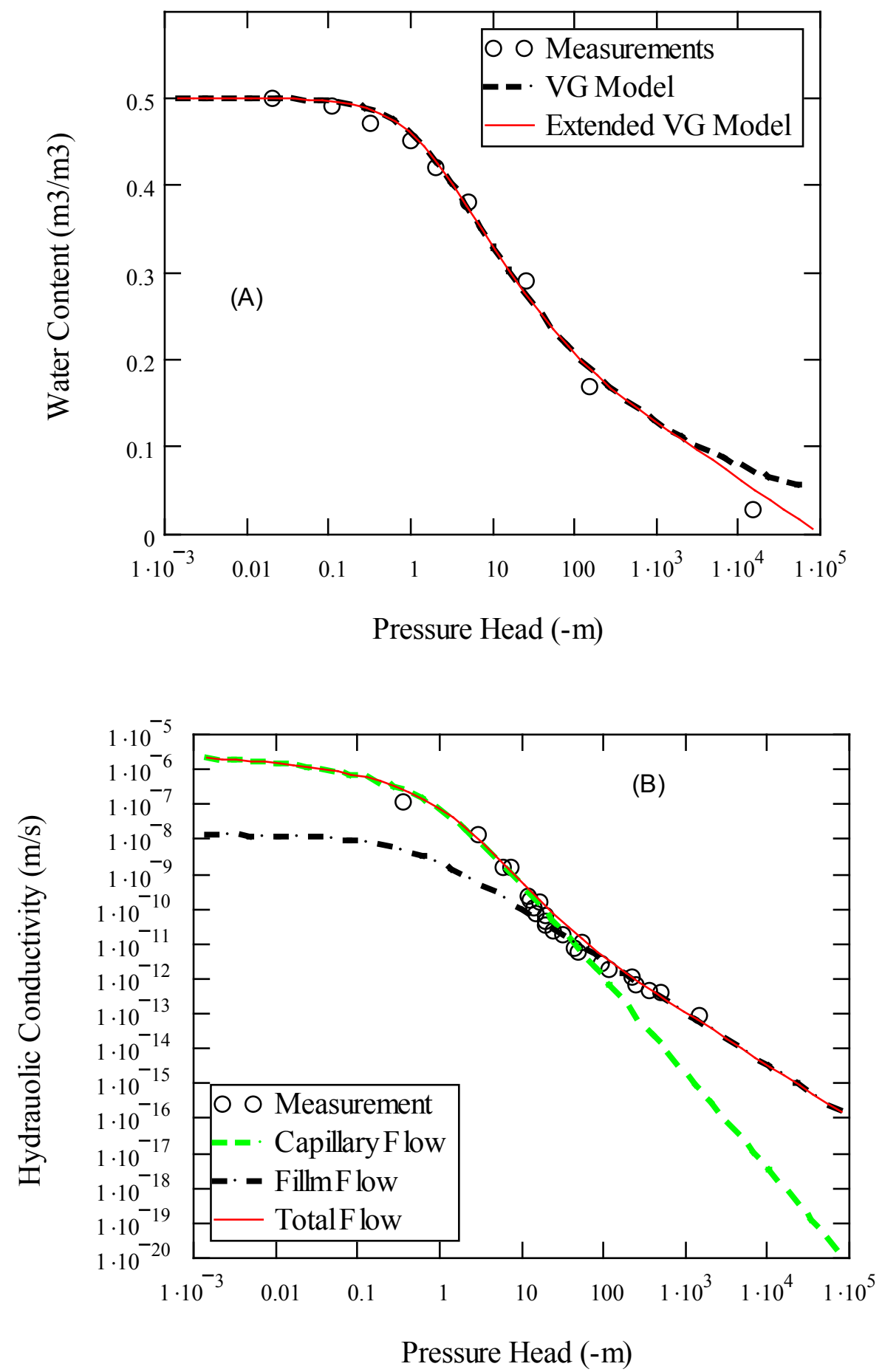

Figure 3.3. The Water Retention (A) and Hydraulic Conductivity (B) of the Clay Loam (soil \#3 in Table 3.1) 

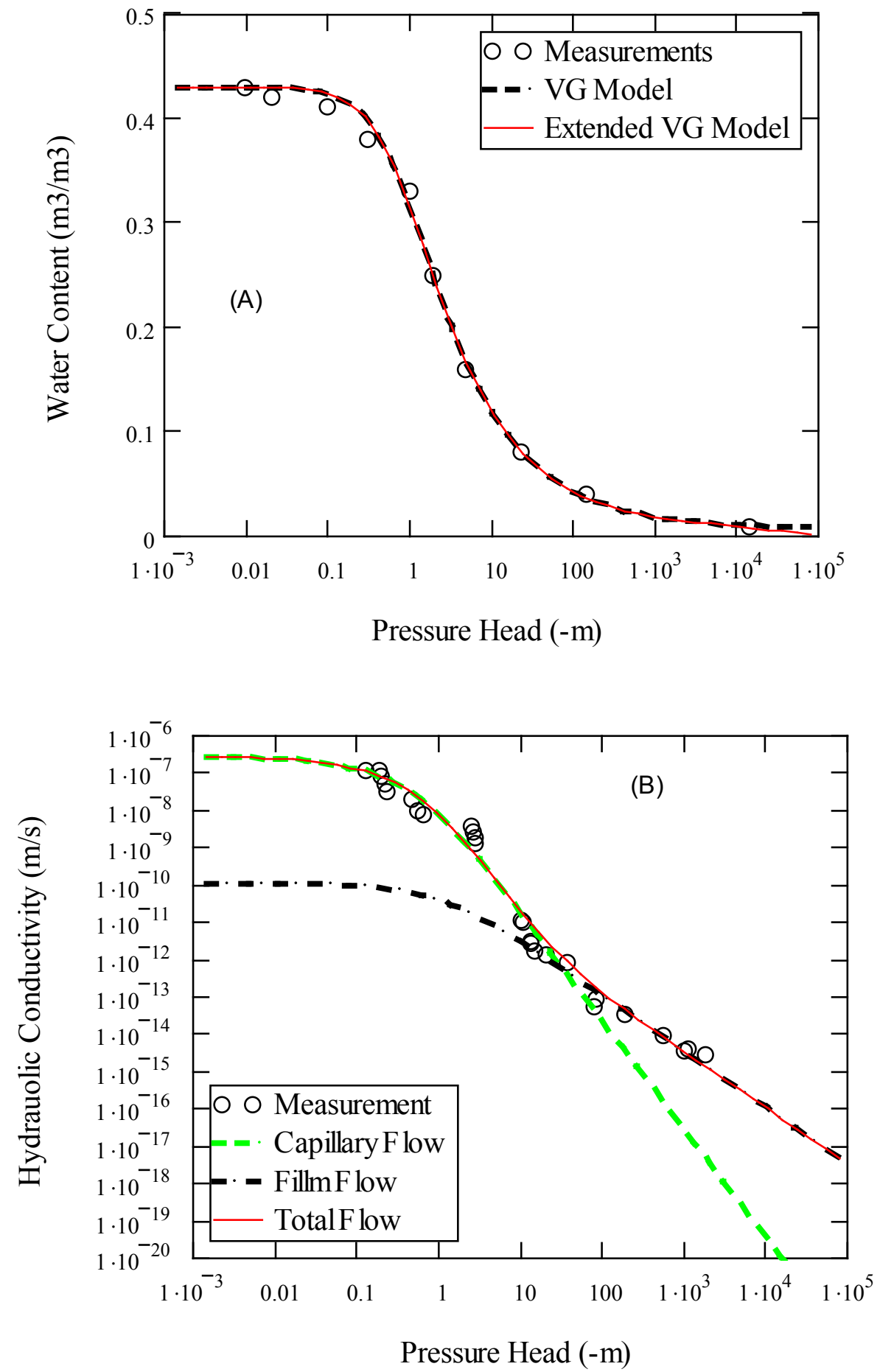

Figure 3.4. The Water Retention (A) and Hydraulic Conductivity (B) of the Sandy Loam (soil \#4 in Table 3.1) 

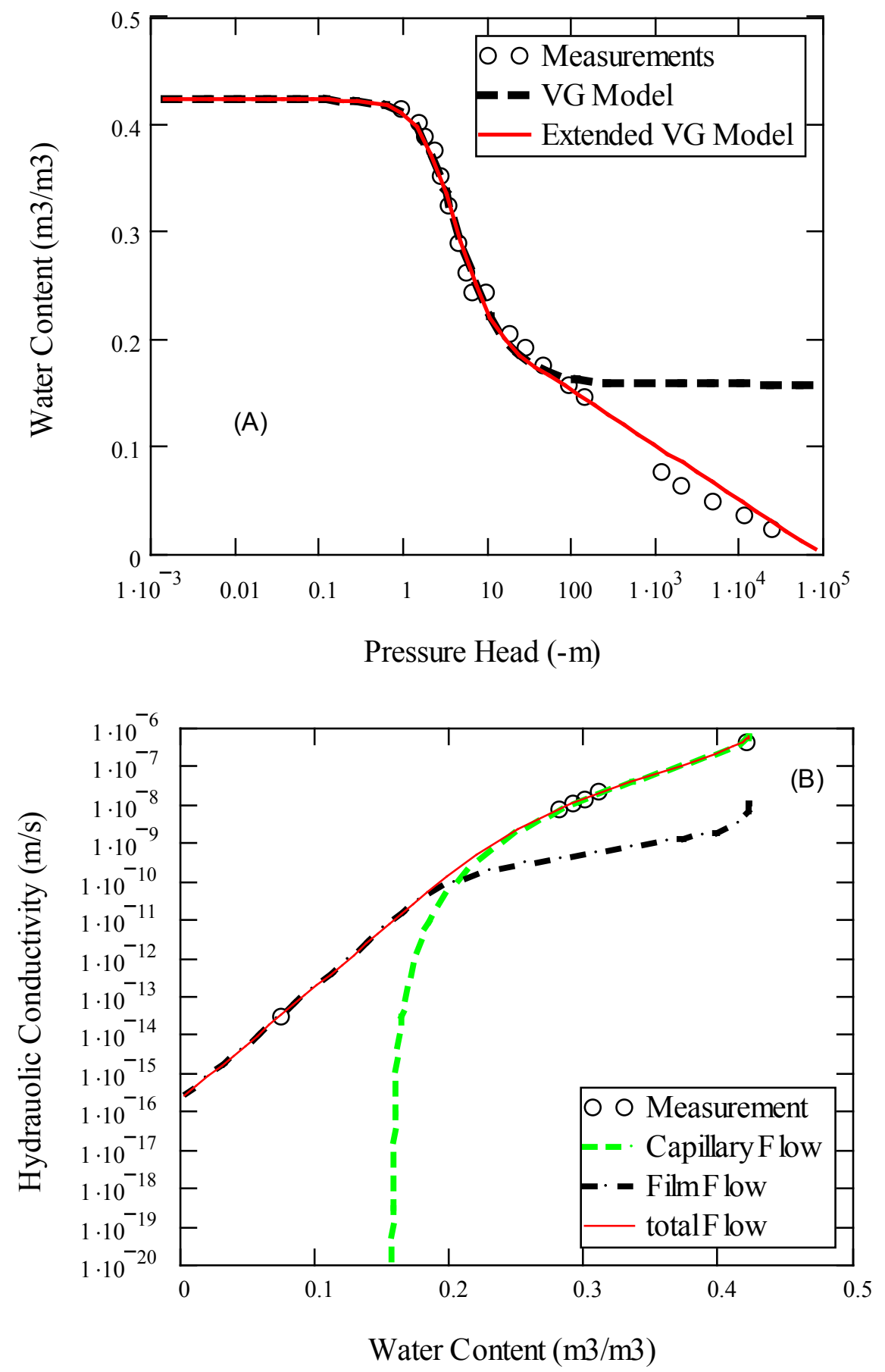

Figure 3.5. The Water Retention (A) and Hydraulic Conductivity (B) of the Adelanto Soil (soil \#5 in Table 3.1) 

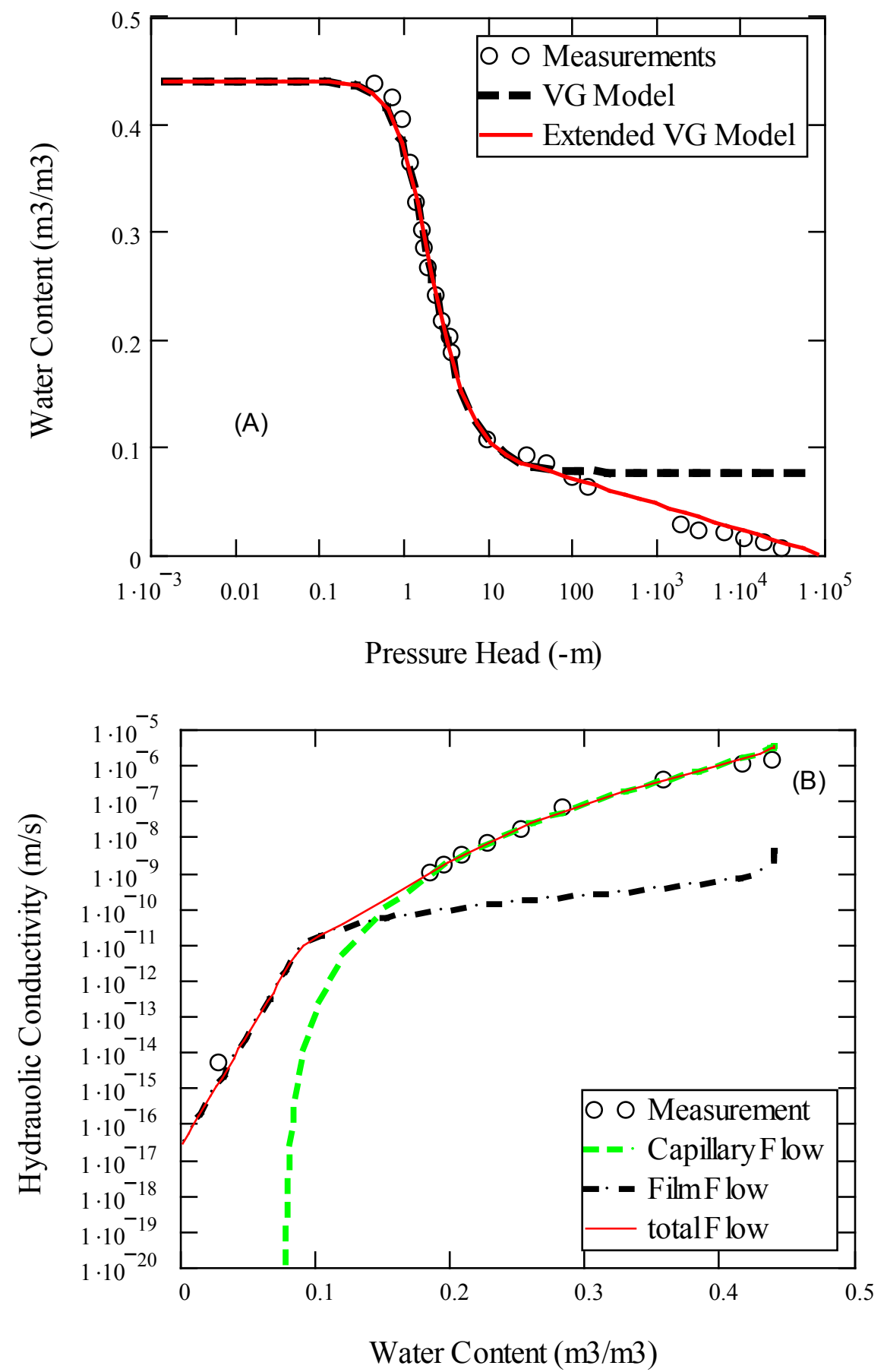

Figure 3.6. The Water Retention (A) and Hydraulic Conductivity (B) of the Pochappa Soil (soil \#6 in Table 3.1) 


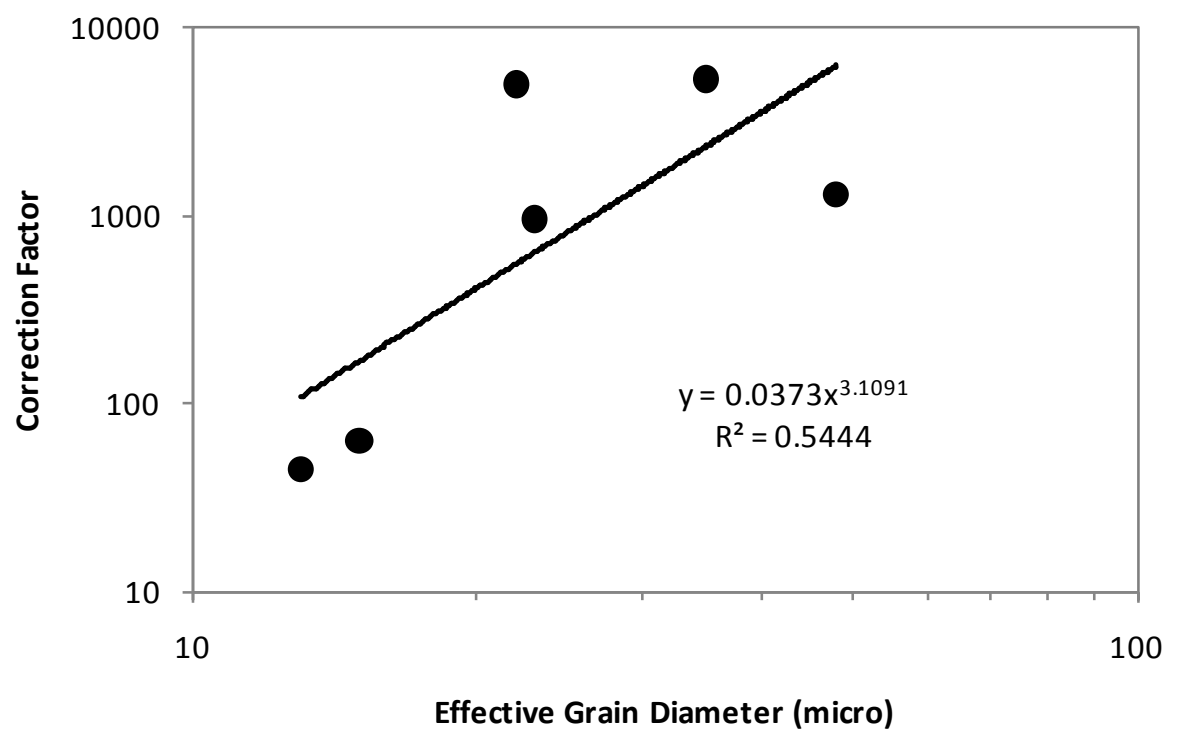

Figure 3.7. The Correction Factor for Film Flow Versus the Effective Grain Diameter 


\subsection{References}

Bird RB, WE Stewart, and EN Lightfoot. 1960. Transport Phenomena. P. 37-41, John Wiley, New York.

Brooks RH and AT Corey. 1966. "Hydraulic properties of porous media affecting fluid flow." Proc. ASCE J. Irrig. Drain. Div. 92:61-88.

Burdine NT. 1953. "Relative permeability calculation from pore-size distribution data." Trans. AIME 198:71-78.

Campbell GS. 1974. "A simple method for determining unsaturated conductivity from moisture retention data." Soil Sci. 117:311-314.

Campbell GS and S Shiozawa. 1992. "Prediction of hydraulic properties of soils using particle-size distribution and bulk density data." In: International Workshop on Indirect Methods for Estimating the Hydraulic Properties of Unsaturated Soils, edited by MT van Genuchten, RJ Leij, and LJ Lund, 317-328, University of California, Riverside.

Fayer MJ and CS Simmons. 1995. "Modified soil water retention functions for all matric suctions." Water Resour. Res. 31:1233-1238.

Fisher RA. 1926. "On the capillary forces in an ideal soil; correction of formulae given by WB Haines." J. Agric. Sci. 16:492-503, doi:10.1017/S0021859600007838.

Gardner WR and FJ Miklich. 1962. "Unsaturated conductivity and diffusivity measurements by a constant flux method." Soil Sci. 93:271-274.

Jackson RD. 1963. "Temperature and soil-water diffusivity relations." Soil Sci. Soc. Am. Proc. 27:363-366.

Jackson RD. 1964. "Water vapor diffusion in relatively dry soil, 1, Theoretical considerations and sorption experiments." Soil Sci. Soc. Am. Proc. 28:172-176.

Jackson RD, RI Reginato, and CHM Van Bavel. 1965. "Comparison of Measured and Calculated Hydraulic Conductivities of Unsaturated Soils." Water Resour. Res. 1:375-380.

Liu HH. 2004. "A constitutive-relationship model for film flow on rough fracture surfaces." Hydrogeology J. 12:237-240.

Mualem Y. 1976a. "A new model for predicting the hydraulic conductivity of unsaturated porous media." Water Resour. Res. 12:513-522.

Mualem Y. 1976b. "A catalogue of the hydraulic properties of unsaturated soils." Res. Praj. Rep. 442, Technion, Israel Inst. of Technol., Haifa.

Pachepsky YA, RA Shcherbakov, G Varallyay, and K Rajkai. 1984. “On obtaining soil hydraulic conductivity curves from water retention curves" (in Russian). Pachvavedenie10:60-72. 
Peters A and W Durner. 2008. "A simple model for describing hydraulic conductivity in unsaturated porous media accounting for film and capillary flow." Water Resour. Res. 44:W11417, doi:10.1029/2008WR007136.

Ross PJ, J Williams, and KL Bristow. 1991. "Equation for extending water-retention curves to dryness." Soil Sci. Soc. Am. J., 55:923-927.

Rossi C and JR Nimmo. 1994. "Modeling of soil water retention from saturation to oven dryness." Water Resour. Res., 30:701-708.

Tokunaga TK. 2009. "Hydraulic properties of adsorbed water films in unsaturated porous media." Water Resour. Res., 45:W06415, doi:10.1029/2009WR007734.

Tuller M and D Or. 2001. "Hydraulic conductivity of variably saturated porous media: Film and corner flow in angular pore space." Water Resour. Res. 37:1257-1276.

van Genuchten MTh. 1980. "A closed form equation for predicting the hydraulic conductivity of unsaturated soils." Soil Sci. Soc. Am. J. 44:892-898.

Webb SW. 2000. "A simple extension of two-phase characteristic curves to include the dry region." Water Resour. Res. 36:1425-1430.

Zhang ZF, AL Ward, and GW Gee. 2003. "Describing the unsaturated hydraulic properties of anisotropic soils using a tensorial connectivity-tortuosity (TCT) concept." Vadose Zone Journal 2(3):313-321. 



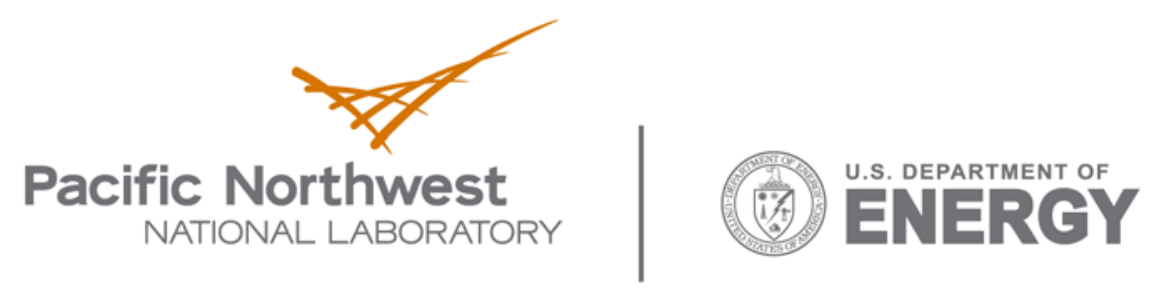

902 Battelle Boulevard

P.O. Box 999

Richland, WA 99352

1-888-375-PNNL (7665)

www.pnl.gov 